\title{
Presynaptic Inhibition of Primary Afferent Transmitter Release by 5-Hydroxytryptamine at a Mechanosensory Synapse in the Vertebrate Spinal Cord
}

\author{
Keith T. Sillar and A. John Simmers ${ }^{a}$ \\ Gatty Marine Laboratory, School of Biological and Medical Sciences, University of St. Andrews, St. Andrews, Fife KY16 \\ 8LB Scotland
}

The effects of the neuromodulatory monoamine 5-HT (serotonin) on a cutaneous mechanosensory (Rohon-Beard, $R-B$ neuron) pathway in the spinal cord of postembryonic Xenopus laevis tadpoles have been examined. In paralyzed animals, exogenous 5-HT at 1-10 $\mu \mathrm{M}$ reversibly inhibits (within 1-2 $\mathrm{min}$ ) the activation of fictive swimming in response to electrical stimulation of R-B free nerve endings in the skin.

At threshold stimulus intensities for swimming under control conditions, intracellularly recorded EPSPs in contralateral motoneurons are completely abolished by 5 -HT without any obvious change in neuronal conductance or membrane potential. However, increasing the stimulus voltage can activate swimming with enhanced motor burst discharge on each cycle (Sillar et al., 1992). This suggested that 5-HT inhibits the swim-initiating pathway rather than the motor rhythm-generating circuitry itself.

Extracellular recordings from the central projections of R-B neurons indicated that the amine does not impair the generation of mechanoafferent impulses or their propagation into the spinal cord. However, 5-HT application blocks impulse activity in dorsolaterally positioned sensory interneurons (DLis) that are contacted by $R-B$ neurons, suggesting that 5-HT acts at R-B to DLi synapses in the dorsal cord.

By recording with microelectrodes from DLis, we find that skin stimulus-evoked EPSPs at this first-order synapse in the swim-initiating pathway are reversibly suppressed by 5-HT. No obvious change in DLi membrane potential or conductance could be detected during the inhibition, suggesting a presynaptic site of action for $5-\mathrm{HT}$.

To investigate this suggestion further, the effects of 5-HT on the spontaneous release of R-B sensory transmitter (excitatory amino acid, EAA) were examined, again by recording postsynaptically from DLis. In quiescent preparations, DLis receive spontaneous glycinergic, GABAergic, and EAA receptor-mediated PSPs. The inhibitory potentials are abol-

\footnotetext{
Received June 17, 1993; revised Oct. 4, 1993; accepted Oct. 19, 1993.

This work was supported by research grants from the Royal Society and the Wellcome Trust (to K.T.S.), by a Royal Society/CNRS Exchange Fellowship (to A.J.S.), and in part by a European Neuroscience Programme Twinning Grant, for which we are grateful. K.T.S. is a Royal Society 1983 University Research Fellow. We thank our colleagues John Wedderburn, Marie Woolston, and Bob Pitman for helpful discussion and criticism of earlier drafts of the manuscript

Correspondence should be addressed to Keith T. Sillar at the above address.

aPresent address: CNRS et Université de Bordeaux I, Laboratoire de Neurobiologie et Physiologie Comparées, Place du Docteur Peyneau, 33120 Arcachon, France.

Copyright (C) 1994 Society for Neuroscience $0270-6474 / 94 / 142636-12 \$ 05.00 / 0$
}

ished by strychnine and curare, respectively. The excitatory potentials that remain are not blocked by application of the calcium channel blocker cadmium chloride at $1 \mathrm{mM}$, but are suppressed by the EAA receptor antagonist kynurenic acid. They therefore resemble the TTX-resistant EPSPs described previously in Xenopus DLis (Sillar and Roberts, 1991), which are presumed to arise from the spontaneous liberation of EAA transmitter from R-B terminals.

Bath application of 5-HT dramatically reduces the rate of occurrence of these spontaneous EPSPs consistent with a presynaptic locus for the inhibitory effects of 5-HT. Moreover, the reduction in the rate of spontaneous release and the suppression of evoked excitation in response to skin stimulation are comparable in time course and magnitude, implying that the two amine effects are causally related. In contrast, there is no apparent change in the distribution of spontaneous EPSP amplitudes, suggesting that the inhibition of evoked excltation by 5-HT does not additionally rely on a change in presynaptic quantal content or efficacy of postsynaptic EAA receptors.

We conclude that one major site at which 5-HT inhibits R-B sensory pathway function is via a direct activation of 5-HT receptors located on the R-B afferent terminals, which leads to a reduction in the probability of EAA transmitter release onto DLis.

[Key words: Xenopus, afferent synapse, modulation, presynaptic inhibition, 5-HT, transmitter release]

Sensory processing in the vertebrate CNS involves the integration of afferent inputs by complex neuronal circuitry. These networks are not hardwired, however, since the appropriate response to a specific sensory cue depends, in part, upon the behavioral state of the organism at the time. This demands that sensory-processing pathways be adaptable and subject to modulation. Central modulation of sensory processing can be both phasic, that is, related to the precise timing of the afferent signal in relation to movements, and tonic, such that the overall gain of the integration process is regulated over a longer period.

In the spinal cord, phasic modulation of afferent information appears to be an intrinsic feature of the spinal networks that integrate sensory and motor functions. For example, during locomotor rhythm generation, sensory inputs are often gated according to the phase of the movement in which they occur, and here the gating process largely depends upon rhythmic excitatory and inhibitory feedback from the central motor circuitry itself (Sillar and Roberts, 1988b, 1992a,b; Schefchyk et al., 1990). 
The same circuits are, however, also subject to tonic modulatory control from supraspinal influences that descend from the brainstem and higher centers. One major source of modulation involves the release of the monoamine 5-hydroxytryptamine (5HT, serotonin) from the spinal terminals of interneurons that originate in the raphe nucleus of the rostral ventral medulla. The influence of endogenous and exogenous 5-HT on spinal rhythm-generating networks has now been described in a wide range of vertebrate locomotor systems, where the amine's principal effect is to enhance the duration and intensity of motor bursts in each cycle (cat: Barbeau and Rossignol, 1990; lamprey: Harris-Warrick and Cohen, 1985; Christenson et al., 1989; Wallén et al., 1989; rabbit: Viala and Buser, 1969; Xenopus tadpole: Sillar et al., 1992). The descending 5-HT system also plays a role in modulating sensory pathway function, where the major influence is inhibitory, decreasing the gain of sensory integration processes (Hultborn and Illert, 1991). This dual action has led to the proposal that intraspinal 5-HT might be released simultaneously onto both rhythm-generating and sensory-processing networks, facilitating motor output while depressing somatosensory, especially noxious, inputs (Kuypers and Huismann, 1982; Hultborn and Illert, 1991). In this way the responsiveness of an organism to cutaneous inputs could be reduced during periods of intense locomotor output, such as in response to injury or during escape from danger.

In the mammalian spinal cord, the mechanisms of inhibitory action of 5-HT on somatosensory processing in general, and on antinociception in particular, are still unclear. The available evidence suggests that certain actions of 5-HT involve the excitation of local spinal inhibitory interneurons containing GABA (Alhaider et al., 1991) or enkephalin (Jessel and Kelly, 1991). The latter then acts presynaptically on the central terminals of the primary afferents. However, other evidence indicates an additional postsynaptic site of action for both GABA (Alhaider et al., 1991) and enkephalin (Yoshimura and North, 1983) on the membrane of dorsal horn interneurons cxcitcd by the afferents. Although dorsal horn neurons are themselves richly endowed with 5-HT receptors (Yoshimura and Nishi, 1991), electrophysiological evidence for a direct activation of these receptors on afferent terminals is sparse (but see Holz and Anderson, 1984). The demonstration that monoaminergic projections often show axonal varicosities, without obvious conventional synaptic specializations, has led to the proposal that the amines may be liberated in a paracrine fashion onto spinal circuitry (Hultborn and Illert, 1991), thereby influencing a diverse range of possible target neurons simultaneously. The complex organization of mammalian dorsal horn circuitry has thus precluded a detailed understanding of their modulation by descending monoaminergic inputs.

We have chosen to study spinal mechanisms of sensorimotor integration and modulation in a far simpler vertebrate, postembryonic tadpoles of the amphibian Xenopus laevis. Around the time of hatching, the tadpole spinal cord is neuroanatomically simple, containing only about eight classes of differentiated neuron (Roberts and Clarke, 1982). The role of the majority of these neuron types is now largely known, and as a consequence the spinal rhythm-generating circuitry responsible for swimming in Xenopus laevis embryos (stage 37/38, Nieuwkoop and Faber, 1956) is understood in considerable detail (for review, see Roberts, 1990). The functional organization of the spinal cord rhythm-generating circuitry shares many of the essential features found in more complex vertebrates, including excitato- ry amino acid (EAA) receptor-mediated descending excitation (Dale and Roberts, 1985) and reciprocal glycinergic inhibition (Dale, 1985).

Sensory pathways in Xenopus tadpoles are also quite similar to those of adult vertebrates. The trunk skin of the tadpole is innervated by the free nerve endings of a single, homogeneous population of mechanosensory afferents, called Rohon-Beard (R-B) neurons (Hughes, 1957), which respond to transient indentation with one or a few impulses (Clarke et al., 1984). R-B neurons have unmyelinated peripheral neurites, are slowly conducting, and are immunopositive for substance $\mathrm{P}$. In these respects they therefore resemble mammalian nociceptive $\mathrm{C}$ and A- $\delta$ fibers. In addition, the principal fast-acting transmitter of $\mathrm{R}-\mathrm{B}$ neurons in the spinal cord, like other vertebrate afferents including substance $\mathrm{P}$-containing $\mathrm{C}$ and $\mathrm{A}-\delta$ fibers, is an EAA (Sillar and Roberts, 1988b, 1991). The dorsal spinal cord of Xenopus embryos contains two classes of sensory interneuron with ascending projections (Roberts and Clarke, 1982; cf. mammals, Brodal, 1981) that are directly excited by mechanosensory R-B ncurons (Clarke ct al., 1984; Robcrts and Sillar, 1990). The first of these classes, dorsolateral commissural (DLC) interneurons, is excited by R-B cells innervating the skin on the same side of the animal (Clarke et al., 1984; Sillar and Roberts, 1988b), but not those on the opposite side (Roberts and Sillar, 1990). DLC interneurons in turn relay excitation across the spinal cord via their commissural axons to contralateral motoneurons (Roberts and Sillar, 1990). The second class of sensory interneurons is also excited by R-B neurons on the same side as their somata, but they differ from the DLCs in that they are excited by skin stimulation on both sides of the animal. They have not been identified anatomically but have been referred to as DLX interneurons (Roberts and Sillar, 1990). In the present study we refer to these two populations collectively as DL interneurons (DLis).

In this article we examine the effects of 5-HT on the R-B sensory pathway and its role in eliciting reflex and swimming movements. We first show that, in contrast to the facilitatory influence upon rhythmic spinal neurons that generate swimming activity (Sillar et al., 1992), exogenous 5-HT concurrently suppresses the ability of trunk skin stimulation to initiate fictive swimming. The application of 5-HT does not prevent R-B neurons from spiking in response to electrical stimulation of their receptive fields, but rather the amine impairs their excitation of DLis. The possible direct activation of 5-HT receptors on the presynaptic terminals of R-B cells was tested directly by monitoring spontaneous release of EAA transmitter from R-B cells onto DLis (cf. Sillar and Roberts, 1991). The amine dramatically decreases the rate of spontaneous EPSPs recorded in the DLis, but does not affect their amplitude distributions, suggesting that 5-HT impairs the efficacy of primary sensory transmission by reducing the probability of transmitter release from the primary afferent neurons. This indicates a hitherto unreported facet of monoaminergic modulation of somatosensory pathway function and is discussed in the context of possible general organizational features of vertebrate sensory information processing.

A preliminary account of these data has been published previously in abstract form (Sillar et al., 1991).

\section{Materials and Methods}

Experiments were performed on Xenopus laevis tadpoles in the first day after hatching from the egg membrane (developmental stages $38 / 8-42$; 
A Xenopus laevis embryo
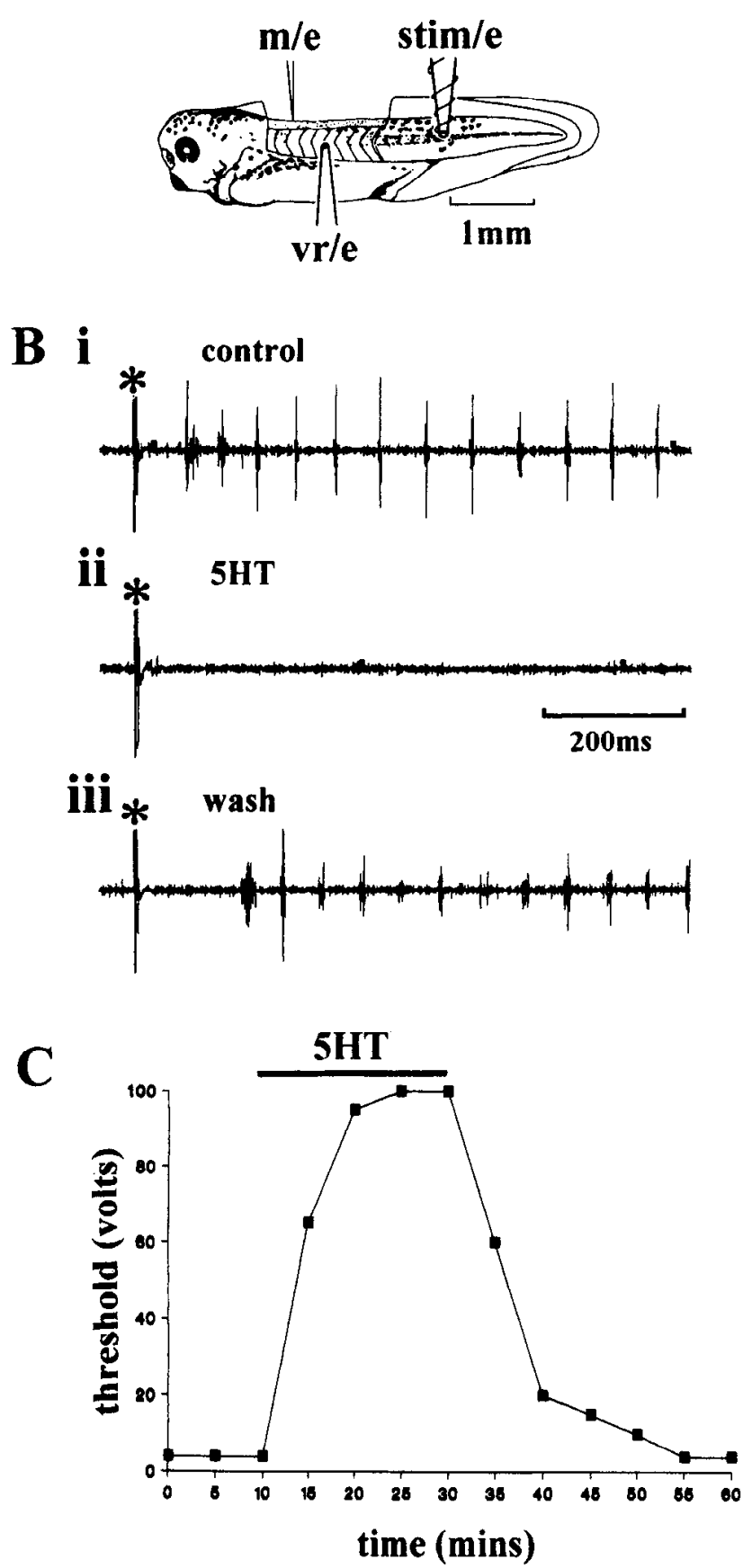

Figure 1. Bath-applied 5-HT inhibits activation of fictive swimming by cutaneous stimulation in Xenopus laevis embryos. $A$, Diagram of embryo at stage $37 / 38$ showing electrode positions for recording extracellularly from a ventral motor root $(\mathrm{vr} / \mathrm{e})$ in an intermyotomal cleft and intrasomatically with a microelectrode $(\mathrm{m} / \mathrm{e})$ from individual neurons within an exposed region of the spinal cord. Reflex responses and episodes of fictive swimming were evoked electrically via an additional suction electrode (stim/e) applied to the tail skin. $B$, Swimming motor output $(i)$ monitored from a ventral root in response to a single brief electrical shock ( $3 \mathrm{~V}$ at $\left.{ }^{*}\right)$ to the caudal trunk skin. In the presence of $2 \mu \mathrm{M}$ 5-HT ( $i i)$, the same stimulus voltage no longer activates swimming, but does after washout in normal saline (iii). $C$. Time course of minimum skin stimulus voltage required to activate swimming before, during, and after exposure to $2 \mu \mathrm{M} 5-\mathrm{HT}$ (applied at bar). Within $10 \mathrm{~min}$ of amine application, the threshold voltage increased reversibly from 3 to $100 \mathrm{~V}$.
Nieuwkoop and Faber, 1956) at temperatures of $20 \pm 2^{\circ} \mathrm{C}$. Although the majority of experiments reportcd here were on hatchling embryos at stage $37 / 8$, the effects of 5-HT on older stage 40 and 42 animals were broadly similar, indicating that the amine's modulation of sensory pathway function is not restricted to a particular stage in early postembryonic development.

Animals were immobilized in $1.25 \mu \mathrm{M} \alpha$-bungarotoxin and secured on their sides to the Sylgard surface of a Perspex platform located in a $2 \mathrm{ml}$ preparation bath. The platform could be rotated about its long axis to facilitate dissection and recording. Preparations were continuously superfused with saline of the following ionic composition (in mM): $\mathrm{NaCl}, 120 ; \mathrm{KCl}, 2.5 ; \mathrm{CaCl}_{2}, 5 ; \mathrm{MgCl}_{2}, 1 ; \mathrm{NaHCO}_{3}, 15 ; \mathrm{pH}$ 7.6. The trunk skin overlying the myotomal muscles on the left side was removed from the level of the otic capsule to the anus using fine etched tungsten needles. Extracellular recordings of motoneuron activity were made with glass suction electrodes placed over intcrmyotomc clefts (cf. Kahn and Roberts, 1982). The myotomes overlying the rostral spinal cord from the otic capsules to the midtrunk region were also removed, to enable extra- or intracellular recording from the exposed spinal cord.

The central compound impulse responses of R-B neurons to peripheral skin stimulation, and in some cases the second-order sensory interneurons excited by R-B cells, were monitored with an extracellular suction electrode placed against the dorsal surface of the cord (cf. Soffe, 1991). Individual sensory interneurons in the dorsal half of the spinal cord and rhythmically active neurons, presumed to be motoneurons, in the ventralmost aspect of the cord were impaled with glass microelectrodes either using capacitance overcompensation or with the aid of a piezoelectric joiting device (Weevers, 1972). Microelectrodes were filled with either $3 \mathrm{~m}$ potassium acetate or $2 \mathrm{~m}$ potassium chloride and had tip resistances of $150-350 \mathrm{M} \Omega$.

A glass suction electrode $(\sim 50 \mu \mathrm{m}$ tip opening) placed on the left or right tail skin at about the level of the anus (cf. Clarke et al., 1984) was used to deliver current pulses ( 0.5 or $1 \mathrm{msec}$ duration) to excite the neurites of underlying R-B neurons. In this way excitatory postsynaptic potentials (EPSPs) were evoked in sensory DLis, and at higher intensities resulted in episodes of rhythmic swimming activity. Fictive swimming could also be evoked through the pineal sensory pathway by dimming the illumination of the preparation (Roberts, 1978).

Pharmacological agents [strychnine sulfate, bicuculline methiodide, $d$-tubocurarine chloride, cadmium chloride, kynurenic acid (KYAC), and 5-HT] were added either directly to the perfusate or, more usually, by switching to a separate saline supply containing the drug. Circulation rates through the recording chamber were $2-5 \mathrm{ml} / \mathrm{min}^{-1}$. Conventional recording and amplification techniques were used throughout. Signals were stored on videotape via a Medical Systems PCM-8 interface and permanent records were made using a Gould digital oscilloscope coupled to a Gould digital plotler, or a Graphtec 7600 Thermalarray recorder. The extracellular data presented here derive from 73 experiments while the intracellular results derive from 10 recordings of sensory interneurons and 13 recordings of presumed motoneurons.

\section{Results}

Exogenous 5-HT inhibits cutaneous activation of swimming

Bath application of 1-10 $\mu_{\mathrm{M}}$ 5-HT to Xenopus embryos in vivo (Fig. 1 $A$ ) reversibly inhibits the ability of cutaneous electrical stimulation to activate fictive swimming activity (Fig. $1 B, C$ ). Tail skin stimulation at voltages sufficient to initiate swimming under control conditions (Fig. $1 \mathrm{Bi}$ ) rapidly (within 1-2 min) failed to evoke swimming in the presence of 5-HT (Fig. 1Bii), although rhythmic activity reappeared with higher stimulus intensities (often by up to $1000 \%$; Fig. 1C). As shown previously (Sillar et al., 1992), swimming activity evoked in the presence of 5-HT involves more intense bursts of ventral root discharge per cycle. The effect often persisted for some time following washout of 5-HT and after the threshold stimulus had returned to control levels (Fig. 1Biii). This suggests that 5-HT is not exerting an inhibitory influence directly on the central rhythmgenerating circuitry, but rather is causing suppression of the afferent pathway that initiates swimming (see also below).

Since the synaptic pathway by which R-B mechanosensory information is conveyed to the motor system is well described 
$\mathbf{A}$

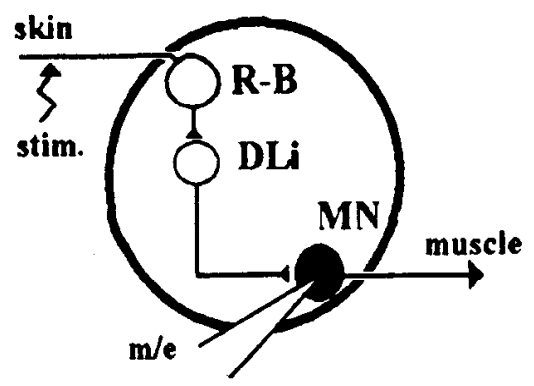

$\mathrm{C}$ i

control

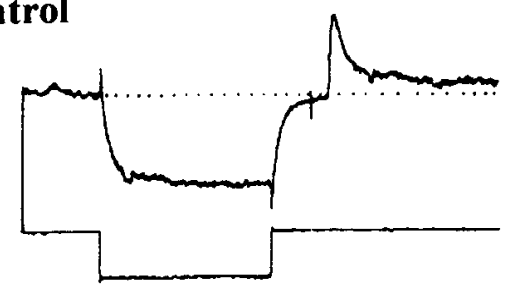

ii

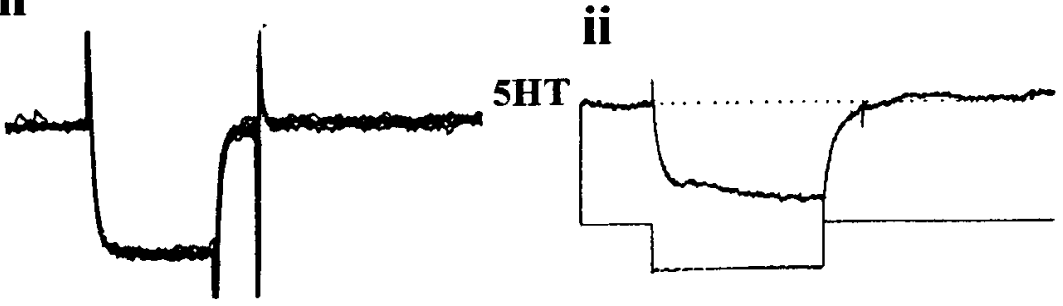

iii

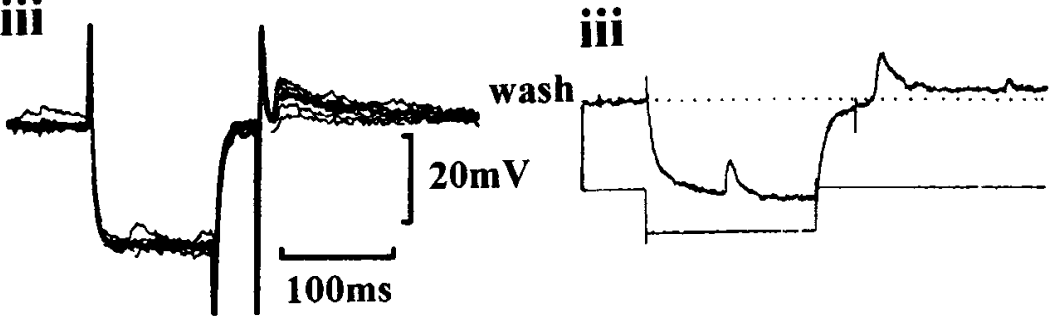

Figure 2. 5-HT completely abolishes excitation of contralateral spinal neurons, presumed to be motoneurons, in response to skin stimulation. $A$, Schematic cross section of the neural circuit that relays excitation from cutaneous Rohon-Beard $(R-B)$ mechanoreceptors across the spinal cord via dorsolateral sensory interneurons $(D L i)$ to contralateral motoneurons $(M N)$ (adapted from Sillar, 1991). $B$ and $C$, Intracellular recordings from two motoneurons showing responses (eight superimposed in $B$; single responses in $C$ ) to constantamplitude $(\sim 0.1 \mathrm{nA})$ hyperpolarizing current pulses (100 msec, $B ; 150 \mathrm{msec}$, $C)$ that precede single electrical shocks to the contralateral tail skin. For both cells $(B, C)$, bath application of $5 \mu \mathrm{M}$ 5-HT (ii) completely, but reversibly (iii), abolished EPSPs evoked by the same levels of cutaneous stimulation under control conditions $(i)$ and without any obvious change in membrane conductance.
(Fig. 2A; see introductory remarks), we were in a position to determine where in this pathway the inhibitory influence of 5-HT occurs. In principle, four sites of action of 5-HT could be involved: (1) the peripheral spike-generating mechanism of the R-B sensory neurons, (2) the release of R-B sensory transmitter, (3) the input and/or output properties of the postsynaptic DLis excited by R-B neurons, and (4) neurons of the motor network.

\section{5-HT blocks sensory transmission to spinal motoneurons}

To test whether cutaneous information continues to have access to the spinal motor circuitry under 5-HT, ventrally positioned rhythmically active neurons, presumed to be motoneurons, were recorded intracellularly (Fig. 2) to examine their crossed excitation during cutaneous R-B stimulation. Under normal saline conditions (Fig. $2 \mathrm{Bi}, \mathrm{Ci}$ ), input to motoneurons in response to contralateral skin stimulation consists of discrete synaptic excitation up to $20 \mathrm{mV}$ in amplitude. If large enough to elicit impulses in the motoneurons, the resulting reflex, which is often followed by swimming, would normally cause the animal to move away from the site of stimulation (see Sillar and Roberts, 1988a). However, this excitation is completely blocked (Fig. $2 \mathrm{Bii}, \mathrm{Cii}$ ), but in a reversible manner (Fig. 2 Biii, Ciii), following bath application of 2-5 $\mu \mathrm{M}$ 5-HT $(n=7)$. Significantly, moreover, this suppression of sensory input occurs without any evident change in resting potential of the motoneurons or their membrane conductance, as indicated by the unaltered voltage excursion in response to constant-amplitude hyperpolarizing current injection. This, together with the apparently total suppression of crossed excitation, suggests a failure in either presynaptic impulses in DLis or in DLi transmitter release in the presence of 5-HT, rather than a direct change in the excitability of the motor system.

\section{5-HT does not affect $R-B$ cell firing}

We next examined the possibility that 5-HT inhibited the spikegenerating mechanism of the cutaneous receptors themselves, thereby preventing access of sensory impulses to the dorsal cord. By increasing a resting conductance for $\mathrm{K}^{+}$ions, for example, 

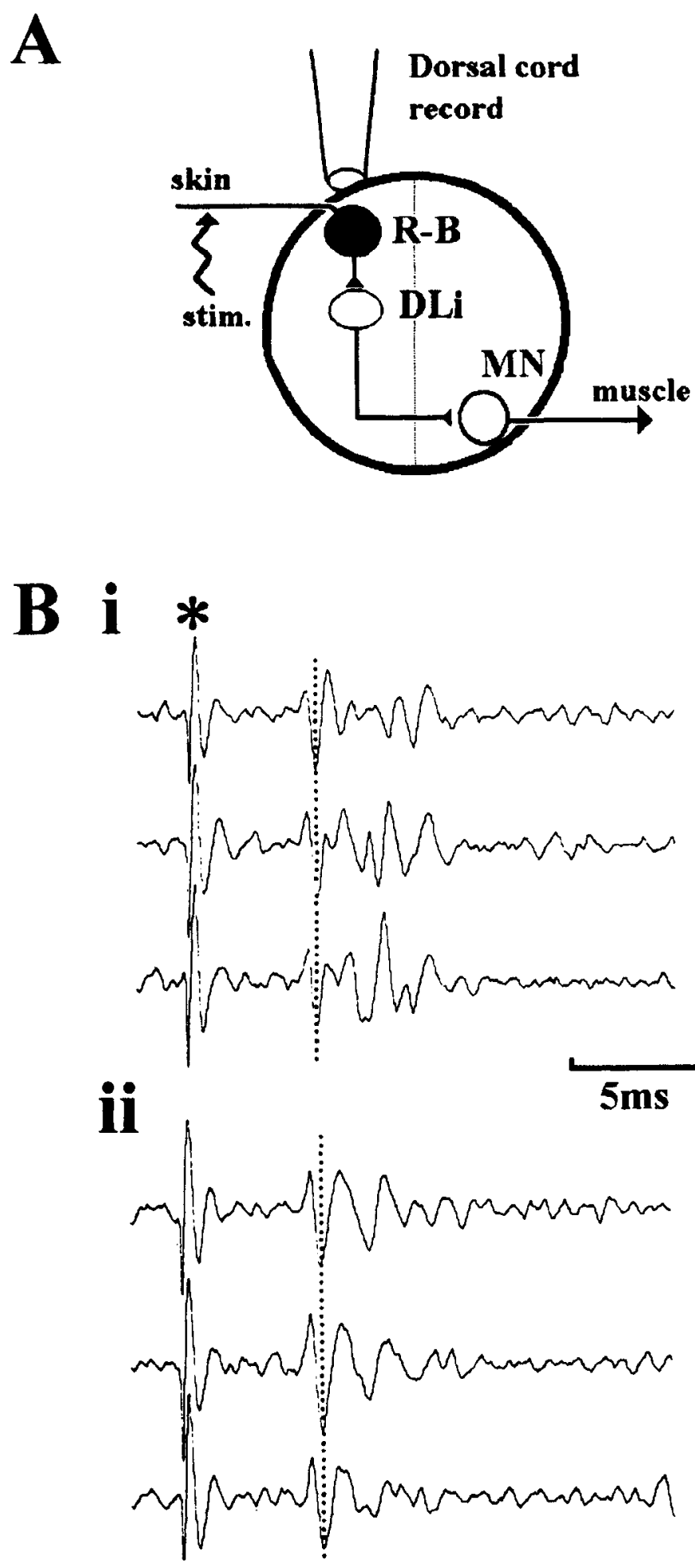

Figure 3. 5-HT does not affect intraspinal transmission of sensory R-B neuron impulses in response to trunk skin stimulation. $A$, Spinal activity of R-B neurons was recorded with an extracellular suction electrode applied to the dorsal surface of the cord. $B i$, Individual cord responses to single shocks applied to the tail skin (at*). The stimulation reliably cvoked compound impulses in the cord after a brief $(\sim 5 \mathrm{msec})$ and constant delay, consistent with the central responses of R-B neurons. $B i i$, These short-latency responses remained in the presence of $5 \mu \mathrm{M}$ 5 - $\mathrm{HT}$, indicating that impulse generation in the primary afferents is unaffected by the amine. as reported for certain central neurons (e.g., Colino and Halliwell, 1987), 5-HT could hyperpolarize R-B cells and render them unresponsive to electrical stimulation. To test this we monitored R-B responsiveness to 5-HT by applying an extracellular suction recording electrode to the dorsal surface of the spinal cord in vivo (Fig. 3A). Since the somata and central axonal projections of R-B neurons constitute the principal cell type in this region of the cord (Roberts and Clarke, 1982; Clarke et al., 1984), focal recordings from this area provide a direct monitor of any R-B impulses arising peripherally (Soffe, 1991). One such experiment $(n=5)$ is shown in Figure $3 B$, where responses to cutaneous stimulation on the left side of the animal were monitored from the dorsal cord surface, slightly ipsilateral to the midline (Fig. 3A). Single stimuli applied to the trunk skin evoked compound responses at a latency $(5-10 \mathrm{msec})$ consistent with the delay time of R-B impulses propagating from the peripheral site of stimulation (Fig. 2Bi; cf. Clarke et al., 1984; Soffe, 1991).

As seen in Figure $3 B i i$, the presence of 5-HT has little qualitative effect on this primary afferent discharge. Although the later component of the response envelope is somewhat less pronounced than under control conditions (compare Fig. 3Bi,Bii), presumably indicating dropout of units other than R-B neurons (see below), a decrease in overall activity commensurate with an amine-induced failure of R-B activation is clearly lacking. The first major conclusion from these experiments, therefore, is that 5 -HT does not block induction of fictive swimming by altering the firing capability of the primary cutaneous receptors, but must be acting at a more central site. Since neither the motor system (Fig. 2) nor the primary afferent spike-generating capability (Fig. 3) is evidently affected by $5-\mathrm{HT}$, we next focused our attention on the possible suppression of transmission at R-B to DLi synapses in the spinal cord.

\section{5-HT inhibits activation of sensory interneurons}

The first clear indication that this is a major target site for aminergic modulation again derived from examining R-B cell responses to skin stimulation with extracellular recordings from the dorsal aspect of the cord (see Fig. $3 A$ ). In a number of experiments $(n=3)$ where the suction electrode was placed more laterally on the cord's surface, the field potential resulting from skin stimulation included a component that occurred later than that attributable to R-B neurons alone (Fig. $4 A i, B i$ ). This secondary activity closely followed and overlapped the short-latency R-B response, suggesting that it constituted firing in the DLis that are directly excited by EAA release from R-B neurons (Sillar and Roberts, 1988b). Consistent with this notion, when the preparation of Figure 4 was bathed in $1 \mathrm{~mm} \mathrm{KYAC}$, a broadspectrum EAA receptor antagonist, to block sensory synapses, the later component of the cord response was reversibly diminished (Fig. 4Ai-Aiii). This confirms that under control conditions the short-latency response involves R-B impulses (see also Fig. $3 B$ ) that normally lead to, and are followed by, activation of postsynaptic DLis.

Following recovery of control R-B plus DL cord responses by washing in normal saline (Fig. 4Aiii,Bi), the preparation was then bathed in $5 \mu_{\mathrm{M}}$ 5-HT (Fig. 4Bii) and the effects compared with EAA receptor blockade (Fig. 4Aii). As with KYAC, the early component of the cord potential remained, albeit diminished in the presence of 5-HT, but significantly, the later component was again abolished. This strongly suggests, therefore, that the suppressive action of 5-HT on the spinal sensory path- 

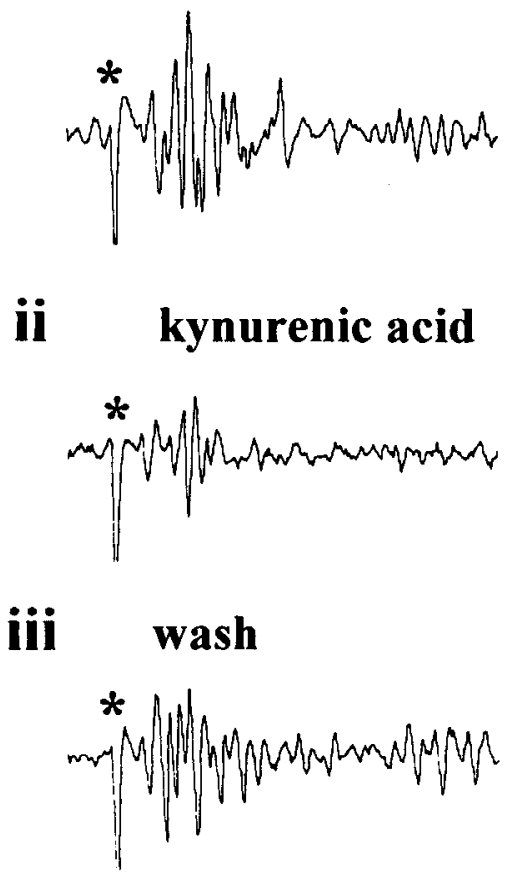
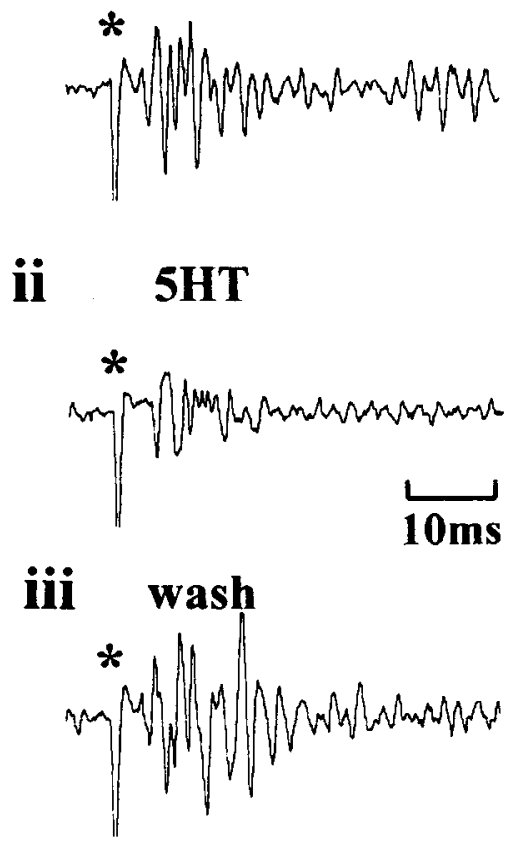

Figure 4. 5-HT does not inhibit firing in R-B ncurons but suppresses impulses in postsynaptic sensory interneurons. $A$, Complex response recorded extracellularly from the dorsolateral surface of the spinal cord to a single cutaneous stimulation $\left(i\right.$; applied at $\left.{ }^{*}\right)$. The cord response is curtailed in the presence of the EAA receptor antagonist KYAC (1 mM; ii), known to block excitation of DLis by R-B neurons (Sillar and Roberts, 1988b), and the remaining shortlatency response is presumed to be from the mechanoreceptors alone. The longer-latency (DL) component returns on wash with normal saline (iii). $B$, Subsequent application of $5 \mu \mathrm{M} 5-\mathrm{HT}$ to the same preparation under control conditions (i) mimics the affects of KYAC, causing dropout of the later component to leave just the R-B response (ii). DL activation returns after wash in normal saline (iii). way occurs principally at the first-order synapse between R-B cells and DLis.

To verify this prediction, we recorded intracellularly from individual DLis (Fig. 5A) and examined the effects of 5-HT on their synaptic responses to R-B cell stimulation (Fig. $5 B, C$ ). In the experiment illustrated in Figure $5 B$, the intensity of skin stimulation had been adjusted so that the excitatory response in the DL cell was maximal, indicating that the free nerve endings of all R-B neurons in the area of skin beneath the stimulating electrode were being activated. Thus, under normal conditions (Fig. 5Bi), single stimuli were followed 1:1 and at constant latency ( $10 \mathrm{msec}$ ) by large-amplitude (up to $40 \mathrm{mV}$ ) EPSPs that triggered action potentials (Fig. 5 Bi,Biil). The application of 5-HT dramatically decreased this sensory activation of the DLi. As seen in Figure $5 \mathrm{Bii}$, the peak amplitude of the compound EPSP evoked by the same stimulus level as before was now reduced to about $10 \mathrm{mV}$ after $5 \mathrm{~min}$ exposure to $5 \mu \mathrm{M} 5-\mathrm{HT}$, a value some $60 \%$ less than that recorded in control saline (Fig. $5 B i i$; compare with $B i, B i i i)$. In all such experiments $(n=6)$ synaptic depression was maximal within $5 \mathrm{~min}$ exposure to 5-HT, and recovery of control EPSP amplitudes was generally obtained upon washout with normal saline (Fig. 5 Biii). In another experiment, illustrated in Figure $5 C$, the skin stimulus strength was set to threshold for a single, presumably unitary, EPSP in the recorded DLi. Here again, 5-HT application reversibly reduced and sometimes completely blocked evoked afferent transmission.

These experiments thus confirm that a major target for 5-HT's inhibitory action on the R-B sensory pathway is at the synapses between the primary afferents and sensory interneurons in the dorsolateral cord. Two general mechanisms could subserve aminergic modulation at this synapse; either 5-HT acts directly on the postsynaptic membrane, decreasing DI, responsiveness to R-B cell excitation, and/or 5-HT acts presynaptically by mod- ulating transmitter release from the R-B terminals themselves. We found no evidence for any change in DL membrane conductance during 5-HT application (Fig. 5B,C), but these experiments could not exclude the possible intervention of second messenger pathways activated by 5-HT in these postsynaptic neurons. However, direct evidence for a presynaptic site of action was obtained by the following experiments in which the effects of 5-HT on the spontaneous release of EAA transmitter from R-B terminals was examined.

\section{Spontaneous release of $E A A$ from $R-B$ terminals}

In quiescent preparations, DLis receive apparently spontaneous synaptic potentials that are both depolarizing and hyperpolarizing in sign (Sillar and Roberts, 1991). As seen in Figure 6A, the depolarizing potentials remain in the presence of bath-applied strychnine $(10 \mu \mathrm{M})$ and $d$-tubocurarine $(100 \mu \mathrm{M})$, previously shown in Xenopus embryos to block both evoked and spontaneous IPSPs mediated by glycine and GABA, respectively. That these spontaneous depolarizing potentials do not rely upon impulse-evoked release of transmitter was suggested by their insensitivity to TTX (Sillar and Roberts, 1991), and is further confirmed in Figure $6 \mathrm{~B}$, where $1 \mathrm{~mm}$ cadmium chloride was applied to block voltage-gated $\mathrm{Ca}^{2+}$ currents and thereby abolish evoked transmitter release. Rather than diminishing spontaneous release, however, cadmium caused a slow progressive increase in frequency of EPSPs recorded in DLis (Fig. $6 C$ ). A similar phenomenon has been observed at invertebrate sensorimotor synapses in culture (Dale and Kandel, 1990) and at the vertebrate neuromuscular junction (Trosper and Philipson, 1983), where the long-term enhancing effect of $\mathrm{Cd}^{2+}$ on spontancous transmission was ascribed to its blockade of the $\mathrm{Ca}^{2+} / \mathrm{Na}^{+}$exchanger, thereby gradually elevating levels of free $\mathrm{Ca}^{2+}$ in the presynaptic terminals. Since the remaining EPSPs were completely abolished by KYAC (Fig. 6D), we conclude 
$\mathbf{A}$

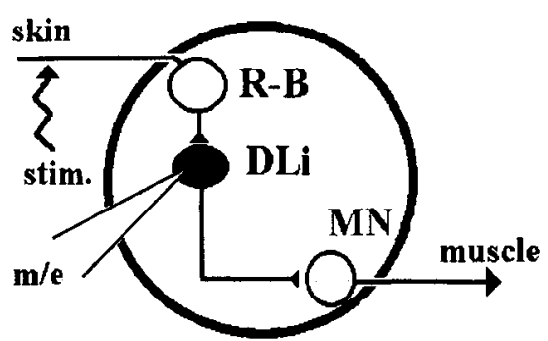

B i

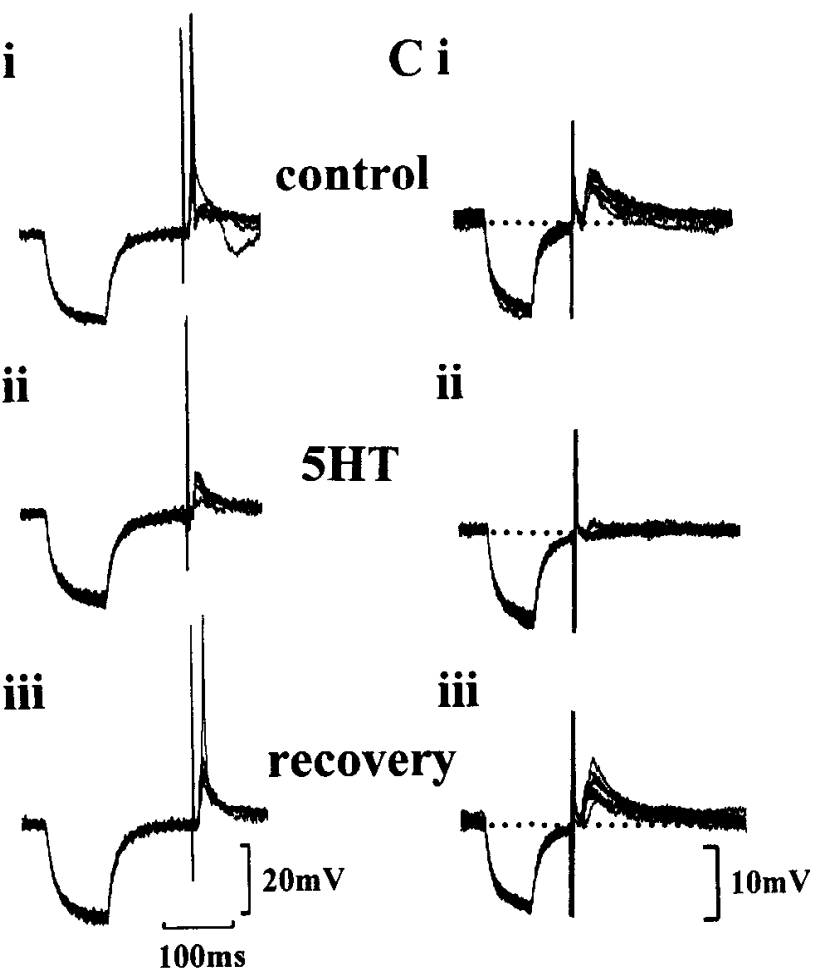

Figure 5. 5-HT diminishes R-B mechanoreceptor-evoked EPSPs in DLis. $A$, Experimental schema involving intracellular recording from a $\mathrm{DLi}$ in the spinal cord while observing the affects of 5-HT on its monosynaptic excitation from R-B cells in response to skin stimulation. $B$ and $C$, Single cutaneous stimuli (five superimposed responses) are followed at constant latency by a compound EPSP that may trigger an action potential (see Bi). Five minutes after exposure to $5 \mu \mathrm{M} 5-\mathrm{HT}$, the EPSP is markedly reduced (ii) to levels below threshold for DL impulse generation (e.g., Bii; compare $B i$ ). Control levels of DLi activation return upon wash in normal saline (iii). In both cases, the depression in sensory excitation by 5-HT is not associated with a change in membrane conductance (as evident from the unaltered responses to hyperpolarizing current injection; $\sim 0.1 \mathrm{nA}$ ), suggesting that 5 -HT is acting presynaptically. Note that the injection of longer pulses to allow complete membrane potential settling (not shown) confirmed that input resistance was not detectably altered in the presence of 5-HT.

that they derive from spontaneous release of sensory transmitter from the central terminals of R-B neurons, the only known source of excitatory input to the DL cells (Sillar and Roberts, 1991., 1988b).

\section{Effects of 5-HT on spontaneous EAA release}

We next tested the relative effects of bath-applied 5-HT on evoked release and on these spontaneous potentials by recording from DLis in the presence of strychnine and curare. If the amine was acting presynaptically, a decrease in the rate of EPSPs in parallel with a decrease in evoked response amplitude would

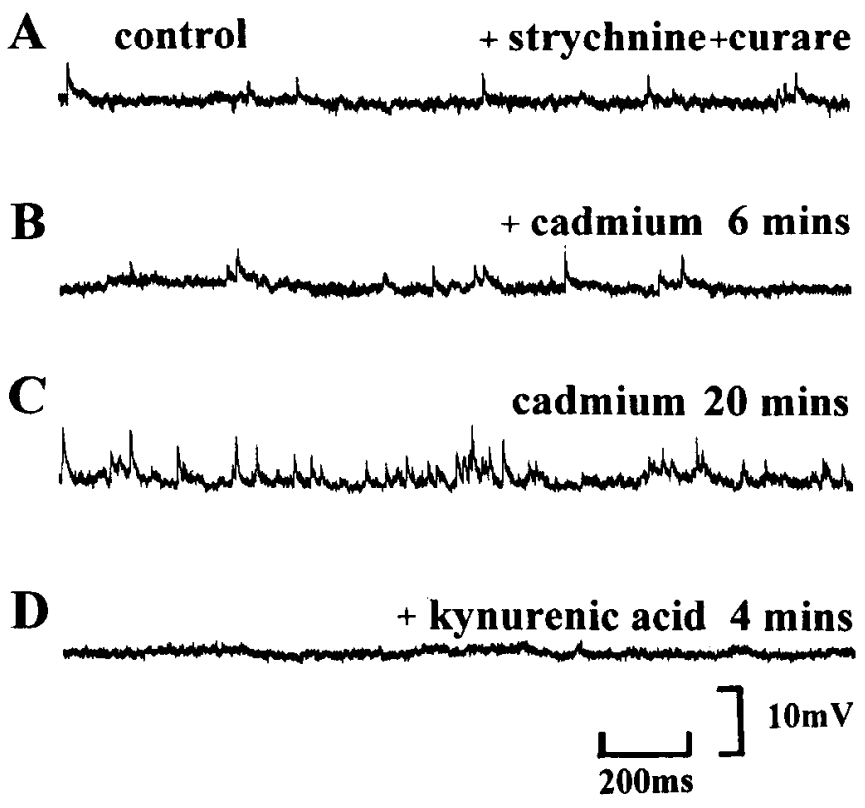

Figure 6. Sensory interneurons receive E $\Lambda$ A-mediated EPSPs that are not dependent upon spike-evoked synaptic transmission. $A$, Prominent depolarizing synaptic potentials recorded intracellularly from a quiescent DL cell in the presence of $10 \mu \mathrm{M}$ strychnine and $100 \mu \mathrm{M}$ curare to block synaptic inhibition from glycine and GABA, respectively. $B$ and $C$, The spontaneous EPSPs are not dependent upon $\mathrm{Ca}^{2+}$ influx to the presynaptic terminals since rather than being abolished by $1 \mathrm{mM} \mathrm{CdCl}$ $(B)$, their frequency progressively increased in $\mathrm{Cd}^{2+}(C) . D$, However, the EPSPs are subsequently abolished by $1 \mathrm{mM} \mathrm{KYAC}$, suggesting that they result from spontaneous release of EAA from sensory R-B neurons.

most likely occur. Alternatively, a purely postsynaptic site of action would predict a decrease in the mean amplitude of the EPSPs, without a change in their rate of occurrence.

Such experiments $(n=4)$ are illustrated in Figures 7-9. Within $5 \mathrm{~min}$ after superfusion with $5-\mathrm{HT}$ at $5 \mu \mathrm{M}$, a dramatic decrease in the rate of occurrence of spontaneous EPSPs occurred (Fig. $7 A i, A i i$ ), which was maintained throughout the period (up to $30 \mathrm{~min}$ ) of 5-HT application. In the experiment of Figure 7, for example, the decrease in the mean rate of EPSPs was from 20.6 $\mathrm{Hz}( \pm 1.3 \mathrm{~Hz}$ SD) under control conditions (Fig. $7 \mathrm{Fi}$ ) to $7.6 \mathrm{~Hz}$ $( \pm 1.7 \mathrm{~Hz} \mathrm{SD})$ in the presence of 5-HT (Fig. 7Bii). Similar changes in the rate of EPSPs wcrc observed in three further DLis examined, and in all cases spontaneous frequencies returned approximately to control levels after washout with normal saline (Fig. 7 Aiii, Biii). In all cells, moreover, the decrease in EPSP rate was associated with a corresponding reduction in the amplitude of EPSPs evoked by cutaneous stimulation (see Fig. 9 and below).

In contrast to the reduction in rate of spontaneous EPSPs, their amplitudes showed no apparent modulation by 5-HT. In control conditions in the experiment of Figure 8, for example, individual EPSPs attained amplitudes of up to about $10 \mathrm{mV}$ (Fig. 8A; cf. Sillar and Roberts, 1991), although the amplitude distribution was skewed such that about $80 \%$ fell within the 1$3 \mathrm{mV}$ range (Fig. 8Bi,Biii). During exposure to 5-HT (Fig. $8 A i i, B i i)$, this distribution was maintained, with no significant increase in the percentage of EPSPs appearing at the lower end of the range. Mean EPSP amplitudes before $(2.56 \mathrm{mV}$; Fig. $8 \mathrm{Bi})$, during (2.73 mV; Fig. 8Bii), and following (2.76 mV; Fig. 8Bii) exposure to 5-HT were not significantly different.

From these observations, therefore, we conclude that the abil- 
A i

control

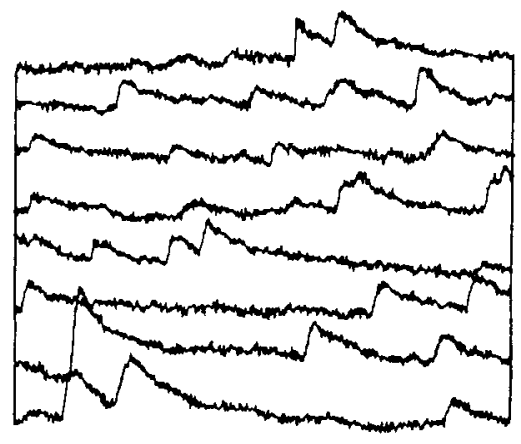

ii

\section{HT}

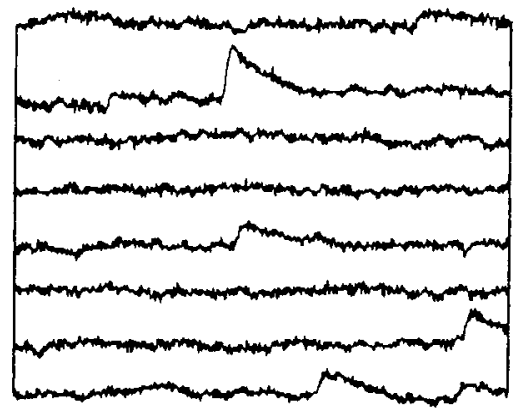

iii

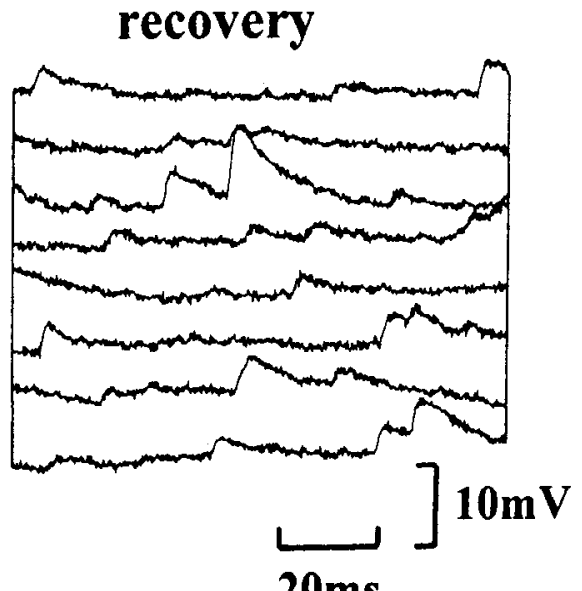

$20 \mathrm{~ms}$
B i

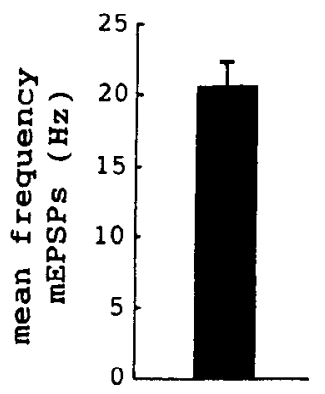

ii

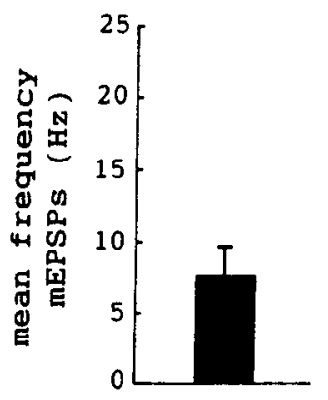

iii

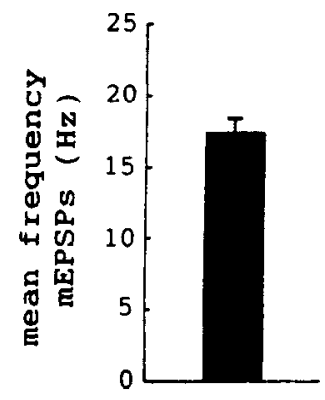

Figure 7. 5-HT reduces the frequency of spontaneous "miniature" EPSPs in DLis. $A$, Sample recordings from a single DL cell before $(i)$, during (ii), and following $($ iii $)$ application of $5 \mu \mathrm{M} 5-\mathrm{HT}$. The traces in each panel are consecutive sweeps from a single $800 \mathrm{msec}$ segment of data. $B$, Histograms of mean frequency of 200 spontaneous EPSPs mcasurcd from records as shown in $A$. Experiment performed in $10 \mu \mathrm{M}$ strychnine and $100 \mu \mathrm{M}$ curare. ity of 5-HT to modulate spontaneous transmission at the firstorder sensory synapse in the Xenopus spinal cord relies upon a reduction in the probability of EAA release from R-B terminals. In general, the reduction in the rate of spontaneous release occurred concurrently with a diminution in the amplitude of EPSPs evoked by cutaneous stimulation. This temporal relationship is illustrated in Figure $9 A$, where the time course of inhibition of spontaneous and evoked events is plotted for the same experiment. Representative samples of evoked responses before, during, and after the 5-HT application are shown in Figure $9 B$. Within $30 \mathrm{sec}$ of 5-HT being applied to the preparation bath, a progressive decline in spontaneous EPSP rate (Fig. $9 A$, circles; from $\sim 5.5$ to $<3 \mathrm{~Hz}$ ) was paralleled by a decrease in evoked
EPSP amplitude (Fig. $9 A$, squares; $B$; from $\sim 30$ to $\sim 10 \mathrm{mV}$ ) over a period of $3 \mathrm{~min}$. Subsequent and parallel recovery in both parameters took place over a $15 \mathrm{~min}$ period in normal saline (not illustrated). This temporal correlation is thus consistent with a causal relationship between the inhibitory effects of 5-HT on spontaneous and evoked release from R-B terminals.

\section{Discussion}

In the spinal cord of most vertebrates, the monoamine 5-HT plays an inhibitory role in the function of neuronal circuits that integrate somatosensory information (Alhaider et al., 1991; Hultborn and Illert, 1991). We describe here that this phenomenon also occurs in the very simple spinal cord of the amphibian 

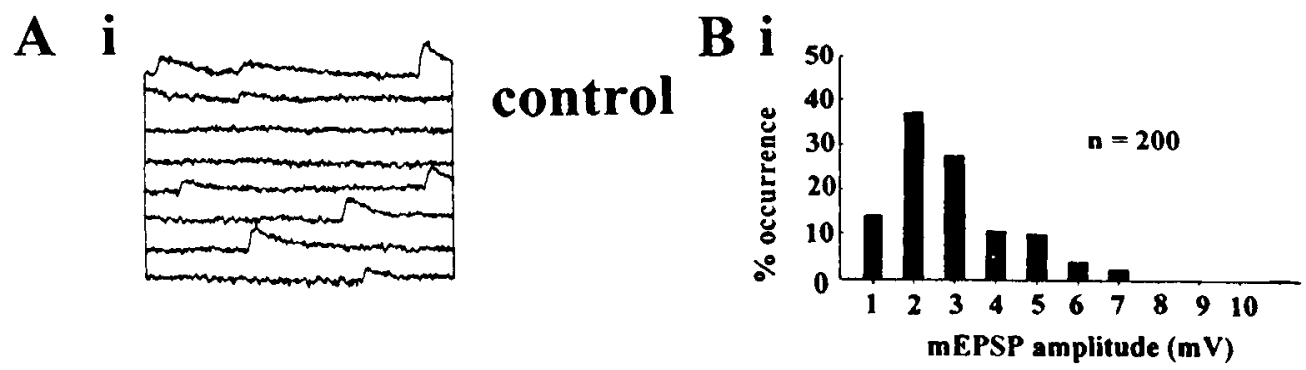

Figure 8. 5-HT does not affect the amplitude distributions of spontaneous "miniature" EPSPs in DLis. $A$. Sample recordings from a single $D L$ cell before (i), during (ii), and following (iii) application of $5 \mu \mathrm{M} 5-\mathrm{HT}$. The traces in each panel are consecutive sweeps from a single $800 \mathrm{msec}$ segment of data. As for the cell of Figure 7, the frequency of EPSPs is markedly and reversibly reduced by the amine. $B$, Amplitude distributions of 200 consecutive EPSPs measured from each of the data segments as shown in $A$. Amplitudes of individual EPSPs were measured directly on a digital oscilloscope and placed in incremental $1 \mathrm{mV}$ bins. The lack of a relative increase in smaller potentials suggests that 5-HT alters neither quantal size nor postsynaptic sensitivity. Experiment performed in $10 \mu \mathrm{M}$ strychnine and $100 \mu \mathrm{M}$ curare.
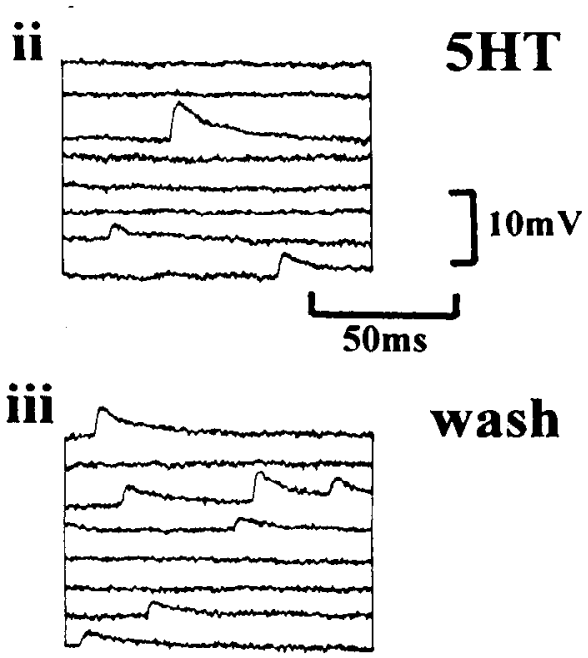
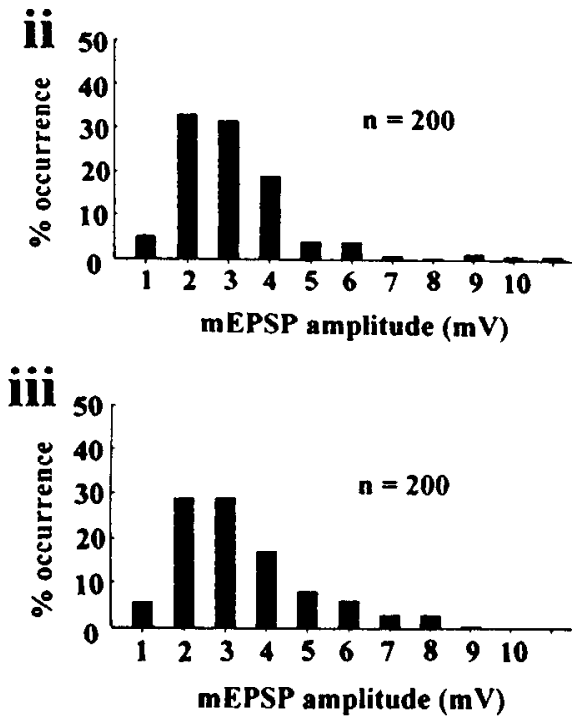

Xenopus laevis at relatively early stages in development. The components of the sensory pathway upon which 5-HT acts are now well described: the primary afferent mechanosensory R-B neurons (Clarke et al., 1984) directly excite dorsolaterally positioned interneurons (DLis) (Sillar and Roberts, 1988b), which in turn relay excitatory information across the spinal cord to the motor circuitry on the side opposite to the cutaneous stimulus, while simultaneously inhibiting the ipsilateral motor system (Sillar and Roberts, 1988b; Roberts and Sillar, 1990). Activation of the crossed excitatory disynaptic pathway underlies a simple behavioral response in which the activation of contralateral musculature bends the organism away from the site of stimulation in a classical avoidance reflex (Sillar and Roberts, 1988a).

Phasic modulation of the R-B pathway during swimming activity has been described in detail previously (Sillar and Roberts, 1988a, 1992a,b). In this study we have begun to investigate the possibility that the same circuit is also subject to tonic modulation by descending systems of the brainstem. The basic phenomenon that we describe-inhibition of cutaneously induced fictive swimming by exogenous 5-HT - occurs centrally in the spinal cord and could, in principle, occur in two ways: 5-HT could inhibit the initiation pathways for swimming and/or it could inhibit the rhythm-generating machinery itself. The latter possibility seems unlikely, however, since increasing the strength of stimulation can overcome 5-HT inhibition of swimming (Fig. 1), and when this occurs the duration and intensity of activity on each cycle of swimming is enhanced (Sillar et al., 1992). Moreover, EPSPs evoked in motoneurons at threshold skin stimulus strengths for swimming in control saline were com- pletely abolished in 5-HT, further suggesting that the amine is acting on the afferent arm of the swim-initiating pathway.

An important site of action of 5-HT on the R-B sensory pathway is at the synapses between the afferents and DLis. First, extracellularly recorded dorsal cord responses indicate that impulses in DLis are dramatically curtailed in the presence of 5-HT (Fig. $4 A$ ), although primary afferent discharge is unaffected (Figs. $3,4)$. Second, direct intracellular recordings from DLis show that their presumed monosynaptic excitation by R-B neurons (Sillar and Roberts, 1988b) is reduced by up to $80 \%$ in the presence of 5-HT (Figs. 5, 9). The apparent lack of conductance change in postsynaptic DLis during 5-HT inhibition indicated a presynaptic site of action, although indirect effects (e.g., via the activation of second messenger pathways in DLis) could not be discounted. Although another possibility is that conductance changes occur distally on DL dendrites and are hence not detectable intrasomatically, the absence of any obvious change in spontaneous EPSP amplitudes appears to eliminate this possibility. However, direct evidence favoring presynaptic modulation derived from examining the effects of 5-HT on the rate of spontaneous release of R-B transmitter onto DLis. Spontaneous EPSPs in DLis have been shown previously (and confirmed here; Fig. 6) to be EAA receptor mediated (Sillar and Roberts, 1991) and independent of spike-evoked neurotransmission. 5-HT dramatically reduced the rate of occurrence of these spontaneous EPSPs (Figs. 7, 8A) and, significantly, both the magnitude and the time course of this reduction paralleled the reduction in excitation of DLis evoked by skin stimulation (Fig. 9). In contrast, no obvious effect on the amplitude of the spontaneous EPSPs could be detected in the same experiments (Fig. 8). The 

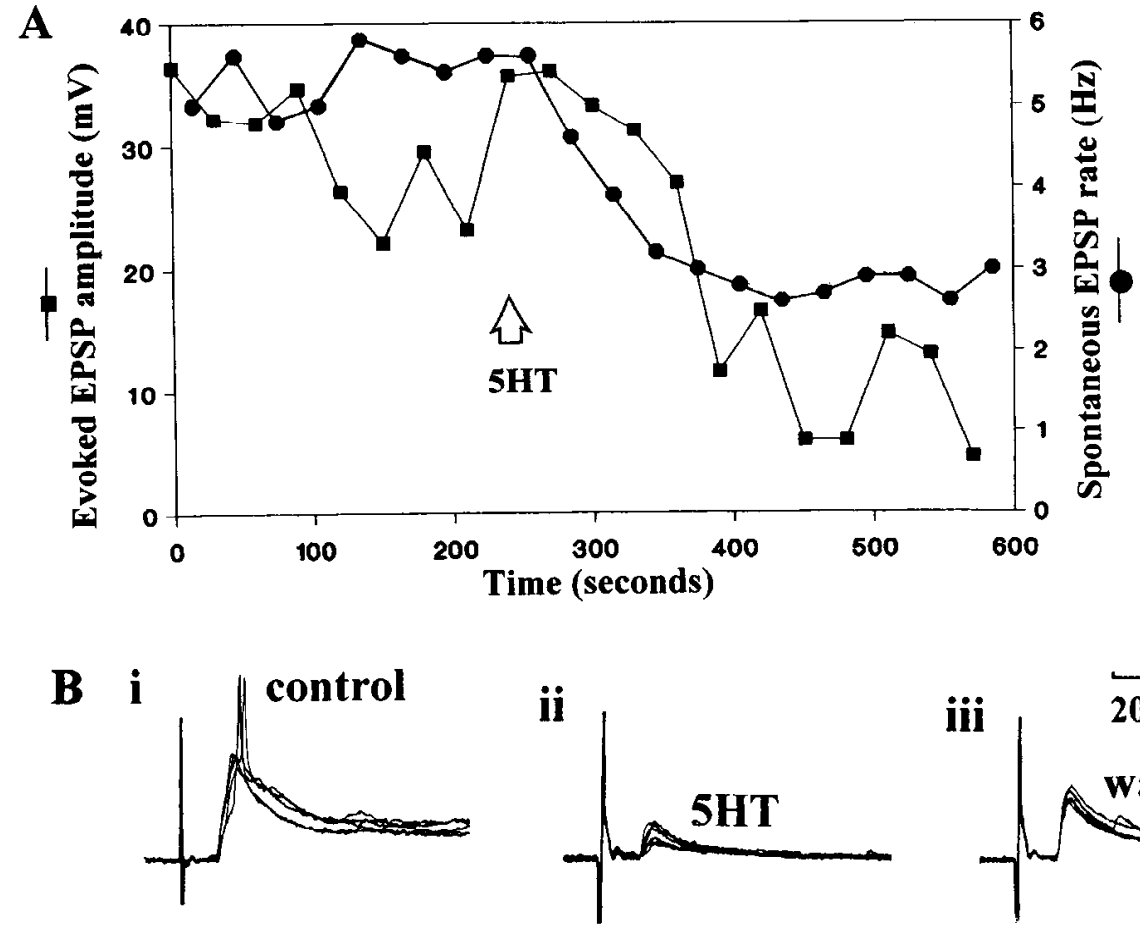

overall distributions of the EPSP amplitudes remained similar, with individuals ranging in size up to about $10 \mathrm{mV}$ and the majority falling in the $1-3 \mathrm{mV}$ category. Although our highresistance electrodes probably limited the accurate discrimination of events below $1 \mathrm{mV}, 5$-HT did not increase the number of smaller EPSPs in the range that we could detect. These observations suggest that the efficacy of the postsynaptic EAA receptors is not significantly affected by $5-\mathrm{HT}$, but rather they favor the conclusion that the inhibitory effects of the amine are mediated by a presynaptic action on the release of EAA transmitter from the R-B afferent terminals.

Research on the actions of 5-HT on mammalian somatosensory pathways has also indicated that the amine acts presynaptically on afferent terminals, but in contrast to the present data 5-HT is thought to excite local GABAergic interneurons rather than directly mediate presynaptic inhibition (Alhaider et al., 1991). The evidence suggests that 5-HT release in the spinal cord activates $5-\mathrm{HT}_{3}$ receptors on the inhibitory interneurons, which in turn release GABA onto the sensory synapses. Although GABA receptors are present on primary afferent $R-B$ neurons at early stages in development (Bixby and Spitzer, 1984), it seems unlikely that such an indirect pathway is playing an equivalent role in the Xenopus spinal cord. In all our experiments on spontaneous EPSPs in DLis we routinely bath applied tubocurarine at $100 \mu \mathrm{M}$, which is known to block GABA receptors in this preparation (Bixby and Spitzer, 1984).

A further related possibility, which cannot be completely discounted here, is that 5-HT activates local enkephalinergic interneurons. In mammals, such an indirect pathway has been proposed to account for the antinociceptive effects that follow stimulation of descending serotonergic pathways: like the spinal GABA pathway (Alhaider et al., 1991), 5-HT is thought to induce the release of enkephalin, which binds to presynaptic receptors on the afferent terminals to block calcium conductances and hence the release of sensory transmitter (Jessel and
Figure 9. Temporal relation between the decrease in rate of spontaneous EPSPs in DLis during application of 5-HT and the reduction in amplitude of spikc-croked EPSPs. $A$, Amplitude of EPSPs (squares) evoked in a DLi by trunk stimulation and frequency of spontaneous EPSPs (circles) before and during exposure to $5 \mu \mathrm{M}$ 5-HT (applied at arrow). Spontaneous frequencies were averaged from $25 \mathrm{sec}$ segments of data in the interval between consecutive evoked responses. $B$, Sample skin stimulus-evoked responses (six superimposed sweeps) before (i), during (ii), and following (iii) application of 5-HT.
Iverson, 1977; Jessel and Kelly, 1991). Although enkephalin receptors have been reported on $\mathrm{R}-\mathrm{B}$ neurons (Bixby and Spitzer, 1983), no evidence for local enkephalinergic spinal interneurons exists. Moreover, preliminary evidence indicates that blockade of enkephalin receptors by naloxone does not eliminate the inhibition by $5-\mathrm{HT}$ of R-B pathway function $(\mathrm{K}$. T. Sillar and C. Reith, unpublished observations). Together these observations lend support to the suggestion that presynaptic inhibition by 5-HT involves the direct activation of 5-HT receptors on R-B terminals, as summarized in Figure 10.

The possibility that 5 -HT receptors are present on vertebrate

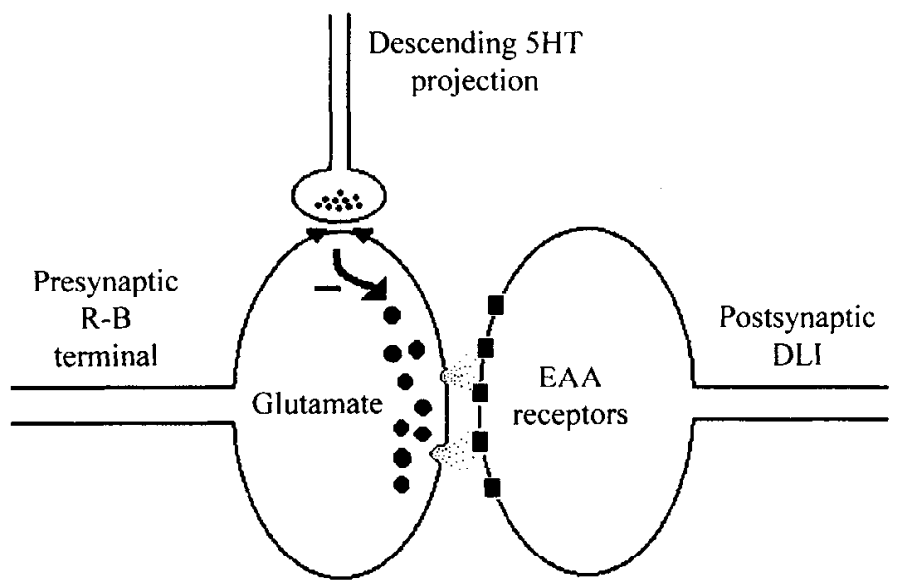

Figure 10. Summary diagram of a direct pathway for presynaptic modulation of primary mechanoreceptor R-B neurons by $5-\mathrm{HT}$ in the Xenopus spinal cord. Intrinsic 5-HT, probably arising from descending spinal projections of the raphe nucleus in the brainstem, activates 5-HT receptors on afferent $R-B$ terminals, thereby inhibiting the release of EAA onto postsynaptic DLis. This tonic modulation thereby suppresses the flow of cutaneous sensory information across the cord to the contralateral motor system (see Discussion for details). 
primary afferents has received relatively little attention. Although earlier studies with somatic recordings from Xenopus R-B neurons failed to find effects of 5-HT on spike height, duration, or resting membrane potential (Bixby and Spitzer, 1984), it is likely from the geometry of R-B cells, with their relatively large somata and long thin axonal projections, that an influence of the amine on membrane polarization, excitability, and transmitter release at electrically distant terminals would not be detected in the soma. In other studies on adult amphibians, however, extracellular measurements of primary afferent depolarization in cutaneous afferent populations did show an apparently direct 5-HT effect, consistent with the prescncc of receptors on their terminals (Holz and Anderson, 1984). In higher vertebrates, evidence for $5-\mathrm{HT}_{3}$ receptors on smalldiameter unmyelinated afferent fibers has been obtained by combining radioligand binding with capsaicin treatment in the rat spinal cord (Hamon et al., 1989). In common with the mammal, preliminary evidence indicates a role for $5-\mathrm{HT}_{3}$ receptors in the 5-HT-induced inhibition of the R-B pathway (Sillar et al., 1991). Interestingly, despite recent attention on the role played by inhibitory interneurons in mediating presynaptic inhibition of somatosensory synapses, evidence for $5-\mathrm{HT}_{3}$ receptors on these intervening cells is so far lacking. It remains feasible, therefore, that while a parallel direct pathway for 5-HT action is resident in the mammalian spinal cord, its affects are obscured by the overlapping influence of complex inhibitory circuitry. In the simple spinal cord of amphibian embryos, the apparent ability of 5-HT to mediate presynaptic inhibition without the intervention of intrinsic spinal inhibitory pathways may point to a developmental precursor in the regulation of somatosensory processing, or to the retention of an ancestral modulatory pathway.

The present study has not addressed the mechanism by which 5-HT inhibits the release of transmitter from R-B terminals. The lack of effect on amplitude distributions of spontaneous EPSPs indicates that the transmitter available for release was not decreased significantly, while the dramatic reduction in the rate of EPSPs suggests that the release mechanism itself was affected. Since the reduction in evoked EPSP amplitude and spontaneous EPSP rate share a very similar time course and magnitude following 5-HT application (Fig. 9), it is conceivable that they are two manifestations of the same underlying process, namely, a reduction in the probability of transmitler release from the afferent terminals. Although this mechanism, which could involve a decrease in the proportion of active release sites (Dale and Kandel, 1990), may alone account for the presynaptic inhibition by $5-\mathrm{HT}$, we cannot yet discount the possibility that during evoked release, 5-HT has parallel effects on spike-induced calcium influx to the terminals, for example.

At the time of hatching, Xenopus tadpoles possess a limited number of differentiated neuron classes compared with adult and higher vertebrates. Although they are at relatively early stages in development, however, a number of cell types correspond with those of adults. In the context of the present study, for example, the primary afferent R-B cells are analogous to mammalian $C$ fibers (see introductory remarks), and they contact DLis that are similar to mammalian dorsal horn projection cells that ascend to the brainstem. In the brainstem of Xenopus tadpoles, 5-HT-containing neurons project from the raphe region in the rostral ventral medulla to the spinal cord and they are most prevalent in the dorsolateral tracts wherein lie the ascending axons of both R-B and DL axons (van Mier et al.,
1986). Thus, an anatomical substrate exists for the direct inhibitory pathway that the present experiments propose. This is in contrast to ventral raphespinal projections that invade the spinal cord subsequent to hatching and apparently modulate rhythmic locomotor output during larval development (Sillar et al., 1992; see below).

In larval Xenopus, bath application of the 5-HT precursor 5-hydroxytryptophan (5-HTP), which enhances the release of endogenous transmitter from serotonergic neurons, facilitates bursts of motor discharge occurring during fictive swimming, mimicking the effects of exogenously applied 5-HT (Sillar et al., 1992). Concurrently, 5-HTP causes a significant decrease in the sensitivity of the R-B swim-initiating pathway (K. T. Sillar and J. F. S. Wedderburn, unpublished observations). Thus, the elements of an intrinsic descending pathway for regulating somatosensory processing are present and functional in the spinal cord at early stages in amphibian development. Since the opposing effects of 5-HT in enhancing rhythm generation and simultaneously inhibiting skin sensory pathways occur in parallel, it is possible that the response of Xenopus tadpoles to strong, potentially harmful cutaneous stimulation is to swim powerfully away and ignore subsequent afferent information which might interfere with this escape behavior.

\section{References}

Alhaider AA, Lei SZ, Wilcox GL (1991) Spinal 5IIT 3 receptor-mediated antinociception: possible release of GABA. J Neurosci 11: 1881-1888.

Barbeau H, Rossignol S (1990) The effects of serotonergic drugs in the locomotor pattern and on cutaneous reflexes of the adult chronic spinal cat. Brain Res 514:55-67.

Bixby JL, Spitzer NC (1983) Enkephalin reduces calcium action potentials in Rohon-Beard neurones in vivo. J Neurosci 3:1014-1018.

Bixby JL, Spitzer NC (1984) The appearance and development of neurotransmitter sensitivity in Xenopus embryonic spinal neurones in vitro. J Physiol (Lond) 353:143-155.

Brodal A (1981) Neurological anatomy in relation to clinical medicine, 3d ed. London: Oxford UP.

Christenson J, Franck J, Grillner S (1989) Increase in endogenous 5-hydroxytryptaminc levels modulates the central network underlying locomotion in the lamprey spinal cord. Neurosci Lett 100:188-192.

Clarke JDW, Hayes BP, Hunt SP, Roberts A (1984) Sensory physiology, anatomy and immunohistochemistry of Rohon-Beard neurones in embryos of Xenopus laevis. J Physiol (Lond) 348:511-525.

Colino A, Halliwell JV (1987) Differential modulation of three separate $\mathrm{K}$-conductances in hippocampal CAl neurons by serotonin. Nature 328:73-77.

Dale N (1985) Reciprocal inhibitory interneurones in the Xenopus embryo spinal cord. J Physiol (Lond) 363:61-70.

Dale N, Kandel ER (1990) Facilitatory and inhibitory transmitters modulate spontaneous transmitter release at cultured Aplysia sensory motor synapses. J Physiol (Lond) 421:203-222.

Dale N, Roberts A (1985) Dual-component amino acid-mediated synaptic potentials: excitatory drive for swimming in Xenopus cmbryos. J Physiol (Lond) 348:527-543.

Hamon M, Gallissol MC, Menard F, Gozlan M, Bouroin S, Verge D (1989) $5 \mathrm{HT}_{3}$ receptor binding sites are on capsaicin sensitive fibres in the rat spinal cord. Eur J Pharmacol 164:315-322.

Harris-Warrick RM, Cohen AH (1985) Serotonin modulates the central pattern generator for locomotion in the isolated lamprey spinal cord. J Exp Biol 116:27-46.

Holz GG IV, Anderson EG (1984) The actions of serotonin on frog primary afferent terminals and cell bodies. Comp Biochem Physiol $77 \mathrm{C}: 13-21$.

Hughes AFW (1957) The development of the primary sensory system in Xenopus laevis (Daudin). J Anat 91:323-338.

Hultborn H, Illert M (1991) How is motor behaviour reflected in the organization of motor systems? In: Motor control: concepts and issues (Humphrey DR, Freund H-J, eds), pp 49-73. New York: Wiley. 
Jessel TM, Iverson LL (1977) Opiate analgesics inhibit substance P release from rat trigeminal nucleus. Nature 268:549-551.

Jessel TM, Kelly DD (1991) Pain and analgesia. In: Principles of neural science, 3d ed (Kandel ER, Schwartz JH, Jessel TM, eds), pp 385399. New York: Elsevier.

Kahn JA, Roberts A (1982) The central nervous origin of the swimming motor pattcrn in cmbryos of Xenopus laevis. J Exp Biol 99:175184.

Kuypers HJM, Huismann AM (1982) The new anatomy of descending brain pathways. In: Brain stem control of spinal mechanisms, Vol 2 (Sjolund B, Bjorklund A, eds) pp 29-54. Amsterdam: Elsevier.

Nieuwkoop PD, Faber J (1956) Normal tables for Xenopus laevis (Daudin). Amsterdam: North-Holland.

Roberts A (1978) Pineal eye and behaviour in Xenopus tadpole. Nature 272:774-775

Roberts A (1990) How does a nervous system produce behaviour: a case study in neurobiology. Sci Prog 74:31-51.

Roberts A, Clarke JDW (1982) The neuroanatomy of an amphibian embryo spinal cord. Philos Trans R Soc Lond [Biol] 296:195-212.

Roberts A, Sillar KT (1990) Characterization of spinal excitatory interneuroncs with commissural projections in Xenopus laevis embryos. Eur J Neurosci 2:1051-1062.

Schefchyk S, McCrea D, Kriellars D, Fortier P, Jordan L (1990) Activity of interneurones within the L4 spinal segment of the cat during brainstem-evoked fictive locomotion. Exp Brain Res 80:290-295.

Sillar KT (1991) Spinal pattern generation and sensory gating mechanisms. Curr Opin Neurobiol 1:583-589.

Sillar KT, Roberts A (1988a) A neuronal mechanism for sensory gating during locomotion in a vertebrate. Nature 331:262-265.

Sillar KT, Roberts A (1988b) Unmyelinated cutaneous afferent neurons activate two types of excitatory amino acid receptor in the spinal cord of Xenopus laevis embryos. J Neurosci 8:1350-1360.

Sillar KT, Roberts A (1991) Segregation of NMDA and non-NMDA receptors at separate synaptic contacts: evidence from spontaneous EPSPs in Xenopus embryo spinal neurones. Brain Res 545:24-32.

Sillar KT, Roberts A (1992a) The role of premotor interneurones in phase-dependent gating of a cutaneous reflex during swimming activity in Xenopus laevis embryos. J Neurosci 12:1647-1657.

Sillar KT, Roberts A (1992b) Phase-dependent modulation of a cutaneous sensory pathway by glycinergic inhibition from the locomotor rhythm generator in Xenopus embryos. Eur J Neurosci 4:1022-1034.

Sillar KT, Simmers AJ, Wedderburn JFS (1991) $5 \mathrm{HT}_{3}$ receptor activation depresses synaptic transmission between cutaneous afferents and sensory interneurones in Xenopus tadpole spinal cord. Soc Neurosci Abstr 17:1006.

Sillar KT, Wedderburn JFS, Simmers AJ (1992) Modulation of swimming rhythmicity by 5 -hydroxytryptamine during postembryonic development in Xenopus laevis. Proc R Soc Lond [Biol] 250:107-1 14.

Soffe SR (1991) Triggering and gating of motor responses by sensory stimulation: behavioural selection in Xenopus embryos. Proc R Soc Lond [Biol] 246:197-203.

Trosper TL, Philipson KD (1983) Effects of divalent and trivalent cations on $\mathrm{Na}^{+} / \mathrm{Ca}^{++}$exchange in sarcoleminal vesicles. Biochem Biophys Acta 731:63-68.

van Mier P, Joosten HWJ, van Rheden R, ten Donkelaar HJ (1986) The development of serotonergic raphespinal projections in Xenopus laevis. Int J Dev Neurosci 4:465-476.

Viala D, Buser P (1969) The effects of Dopa and 5HTP on rhythmic efferent discharges in hindlimb nerves in the rabbit. Brain Res 12: $437-443$.

Wallén P, Buchanan JT, Grillner S, Hill RH, Christenson J, Hokfelt T (1989) The effects of 5 hydroxytryptamine on the afterhyperpolarization, spike frequency regulation and oscillatory membrane properties in lamprey spinal cord neurones. J Neurophysiol 61:759-768.

Weevers R deG (1972) A piezoelectric jolting device for microelectrode penetration. J Physiol (Lond) 303:22P.

Yoshimura M, Nishi S (1991) Patch clamp analysis of serotonin responses in substantia gelatinosa neurons of the rat spinal cord. Soc Neurosci Abstr 17:92.

Yoshimura M, North RA (1983) Substantia gelatinosa neurones hyperpolarized in vitro by enkephalin. Nature 305:529-530. 